\title{
Effectiveness of sodium hypochlorite and sulfinic acid sodium salt treatment on dentin-resin bonding: Long-term durability of one-step self-etching adhesive
}

\author{
Hayaki NAKATANI ${ }^{1}$, Atsushi MINE ${ }^{1}$, Mariko MATSUMOTO ${ }^{2}$, Tomoshige KABETANI ${ }^{1}$, \\ Takuya MINAMINO ${ }^{1}$, Jiro MIURA ${ }^{3}$ and Hirofumi YATANI ${ }^{1}$ \\ ${ }^{1}$ Department of Fixed Prosthodontics, Osaka University Graduate School of Dentistry \\ ${ }^{2}$ Department of Restorative Dentistry, Hokkaido University Graduate School of Dental Medicine \\ ${ }^{3}$ Division for Interdisciplinary Dentistry, Osaka University Dental Hospital \\ Corresponding author, Atsushi MINE; E-mail: mine@dent.osaka-u.ac.jp
} Asuka KAWAGUCHI-UEMURA ${ }^{1}$, Mami HIGASHI ${ }^{1}$, Yuko TAJIRI ${ }^{1}$, Dai IMAI', Ryosuke HAGINO ${ }^{1}$,

\begin{abstract}
This study aimed to evaluate the effect of sulfinic acid sodium salt interposition after acid and sodium hypochlorite treatment (NC treatment) on dentin bonding durability using a mild type one-step self-etching adhesive. Fifteen human third molars were randomly assigned into three experimental groups according to dentin pretreatment before applying the one-step self-etching adhesive: Cont group, without pretreatment; NC group, pretreatment with phosphoric acid and sodium hypochlorite gel; and NC+AC group, additional treatment with sulfinic acid sodium salt followed by the same pretreatment of the NC group. Microtensile bond strength was measured and the pre-treated dentin surface, fracture modes, and bonding interface were observed. The bond strength of the $\mathrm{NC}+\mathrm{AC}$ group was significantly higher than that of the other groups $(p<0.001)$. The dentin-adhesive interface was degraded after 1 year only in the Cont group. Our results demonstrated NC treatment improves bonding durability and application of sodium sulfinic acid salt after $\mathrm{NC}$ treatment improves bonding effectiveness.
\end{abstract}

Keywords: Sulfinic acid sodium salt, Sodium hypochlorite, Mild type one-step self-etching adhesive, Microtensile bond strength, Dentin bonding durability

\section{INTRODUCTION}

Self-etching adhesives, which contain acidic functional monomers to demineralize and infiltrate into dentin substrate simultaneously, are commonly used to prepare dentin surfaces for bonding. These adhesives are thought to require less technical skill than etch-andrinse adhesives with increased durability ${ }^{11}$. However, since self-etching adhesive systems do not require rinsing, a smear layer remains on the dentin surface after applying the adhesives. As mild type adhesives cannot completely dissolve the smear layer ${ }^{2}$, the bonding effectiveness of mild self-etching adhesives to dentin is significantly influenced by the thickness of the smear layer. Belli et al. reported that a thinner smear layer is ideal for higher bonding effectiveness ${ }^{3)}$. Additionally, Suyama et al. found that complete absence of the smear layer significantly improved the bond strength between dentin and resin composite ${ }^{4)}$. Hence, pretreatment to remove the smear layer from dentin surface before applying a self-etching adhesive might be effective to improve the bonding effectiveness.

Since the early 1990s, the use of a total-etching system, which etches both enamel and dentin to remove the smear layer, has gained attention ${ }^{5}$. However, after total etching, the dentin surface is covered with demineralized collagen, making it inaccessible to complete dentin bonding. Consequently, the durability

Color figures can be viewed in the online issue, which is available at J-STAGE.

Received Mar 30, 2017: Accepted Aug 23, 2017

doi:10.4012/dmj.2017-105 JOI JST.JSTAGE/dmj/2017-105 of resin-dentin adhesion can be decreased. To solve this problem, phosphoric acid and sodium hypochlorite $(\mathrm{NaClO})$ application ( $\mathrm{NC}$ treatment) was introduced in the 1990s to remove demineralized collagen fibrils from the adhered dentin surface and expose hydroxyapatite on the surface ${ }^{6-8)}$. Although this treatment, which uses both acid and $\mathrm{NaClO}$ to remove the smear layer and demineralized collagen fibrils, respectively, is presumed to be efficient for dentin-resin bonding in resin cement systems ${ }^{9}$, no research has reported the effectiveness of this treatment method using mild type self-etching adhesive systems, which have been widely used in clinical practice.

$\mathrm{NaClO}$ is also commonly used as an irrigation solution in root canal treatment. Some studies have demonstrated a negative effect of $\mathrm{NC}$ treatment on dentin-resin composite bonding ${ }^{10,11)}$. This negative effect may be due to oxygen production during treatment, resulting in low polymerization rate of the adhesive ${ }^{12)}$. To solve this problem, some studies recommended that additional treatment with antioxidant/reducing agents (e.g., sodium ascorbate, rosmarinic acid, and sulfinic acid sodium salt) can restore the decreased bond strength after $\mathrm{NaClO}$ application ${ }^{13-15)}$. Among these agents, sulfinic acid sodium salt has long been used as a chemical initiator ${ }^{16}$. Hence, we speculated that application of sulfinic acid sodium salt after etching and $\mathrm{NC}$ treatment might be effective to increase the bonding effectiveness.

The objective of this study was to determine the effect of sulfinic acid sodium salt interposition after acid 
and NC treatment on dentin bond durability using a mild type one-step self-etching adhesive. The null hypotheses were as follows:

1) NC treatment has no positive effect on dentin bonding using a mild type one-step self-etching adhesive.

2) Sulfinic acid sodium salt application after NC treatment has no positive effect to increase dentin-resin composite bonding.

3) One-year water storage has no influence on the bond durability between dentin and resin composite.

\section{MATERIALS AND METHODS}

Tooth preparation and resin buildup

Fifteen human third molars, stored in Hank's Balanced Salt solution (HBSS), were used within 6 months after extraction. All teeth were extracted due to periodontal or orthodontic reasons. The experimental protocol was approved by the Ethics Committee of the Osaka University Faculty of Dentistry (No. H26-E6). Midcoronal dentin surface was obtained by removing the occlusal third of the molar crowns using a low-speed diamond saw (Maruto Instrument, Fukuoka, Japan) under water cooling, and a standard smear layer was prepared with 600 grit SiC paper (Fig. 1a). All specimens were randomly assigned into three experimental groups $(n=5)$ following treatment as described below (Table 1, Figs. 1a, b and 2) ${ }^{17}$ ):

1. Control (Cont) group: The manufacturer's instructions were followed using the photo cure adhesive (Clearfil Bond SE ONE, Kuraray Noritake Dental, Tokyo, Japan) and the photo cure resin composite (Clearfil Majesty ES-2, Kuraray Noritake Dental). The resin composite was incrementally built up (two layers of about 2 $\mathrm{mm}$ each). After applying the adhesive, samples were light cured for $10 \mathrm{~s}$ with a cordless lightemitting diode curing light (SATELEC Mini LED 3, Acteon, Merignac, France), which had a maximal light density of $2,200 \mathrm{~mW} / \mathrm{cm}^{2}$. The composite was also light cured for $10 \mathrm{~s}$ per layer, which was considered sufficient to completely cure the resin composite according to the manufacturer's instructions.

2. NC group: The dentin surface was etched for 15 s using $37 \%$ phosphoric acid (K-Etchant gel, Kuraray Noritake Dental), rinsed, and air dried. Then, 10\% NaClO-gel (AD gel, Kuraray Noritake

Table 1 Chemical composition and application of the materials tested

\begin{tabular}{|c|c|c|c|c|c|c|}
\hline & & $\begin{array}{l}\text { Trade } \\
\text { name }\end{array}$ & Lot No. & Manufacturer & Composition & Application \\
\hline \multirow{3}{*}{ Pretreatment } & $\begin{array}{l}\text { Phosphoric } \\
\text { acid }\end{array}$ & $\begin{array}{l}\text { K-Etchant } \\
\text { gel }\end{array}$ & $00525 \mathrm{~A}$ & $\begin{array}{l}\text { Kuraray } \\
\text { Noritake } \\
\text { Dental, } \\
\text { Tokyo, Japan }\end{array}$ & $\begin{array}{l}40 \% \text { phosphoric acid, } \\
\text { water, thickener, } \\
\text { coloring agent }\end{array}$ & $\begin{array}{l}\text { 1. Etch dentin for } 15 \mathrm{~s} \text {. } \\
\text { 2. Rinse for } 15 \mathrm{~s} \text {. } \\
\text { 3. Air dry for } 10 \mathrm{~s} \text {. }\end{array}$ \\
\hline & $\begin{array}{l}\text { Sodium } \\
\text { hypochlorite }\end{array}$ & AD gel & 001023 & $\begin{array}{l}\text { Kuraray } \\
\text { Noritake } \\
\text { Dental }\end{array}$ & $\begin{array}{l}\text { 10-15\% sodium } \\
\text { hypochlorite, } \\
\text { thickener }\end{array}$ & $\begin{array}{l}\text { 1. Apply using a rubbing } \\
\text { motion for } 10 \mathrm{~s} \text {. } \\
\text { 2. Leave for } 50 \mathrm{~s} \text {. } \\
\text { 3. Rinse for } 15 \mathrm{~s} \text {. } \\
\text { 4. Air dry for } 10 \mathrm{~s} \text {. }\end{array}$ \\
\hline & $\begin{array}{l}\text { Sulfinic acid } \\
\text { sodium salt }\end{array}$ & Accel & FV1 & $\begin{array}{l}\text { Sun Medical, } \\
\text { Kyoto, Japan }\end{array}$ & $\begin{array}{l}\text { p-toluenesulfinic } \\
\text { acid sodium salt, } \\
\text { ethanol, water }\end{array}$ & $\begin{array}{l}\text { 1. Apply using a rubbing } \\
\text { motion for } 15 \mathrm{~s} \text {. } \\
\text { 2. Air dry for } 10 \mathrm{~s} \text {. }\end{array}$ \\
\hline Adhesive & - & $\begin{array}{l}\text { Clearfil } \\
\text { Bond SE } \\
\text { ONE }\end{array}$ & CE001 & $\begin{array}{l}\text { Kuraray } \\
\text { Noritake } \\
\text { Dental }\end{array}$ & $\begin{array}{l}\text { 10-MDP, Bis-GMA, } \\
\text { HEMA, hydrophobic } \\
\text { aliphatic methacrylate, } \\
\text { colloidal silica, } \\
\text { sodium fluoride, CQ, } \\
\text { accelerators, initiators, } \\
\text { water }\end{array}$ & $\begin{array}{l}\text { 1. Apply bonding and } \\
\text { leave for } 10 \mathrm{~s} \text {. } \\
\text { 2. Air blow gently for } \\
>5 \mathrm{~s} \text { until the bond } \\
\text { does not move. } \\
\text { 3. Light cure for } 10 \mathrm{~s} \text {. }\end{array}$ \\
\hline Composite & - & $\begin{array}{l}\text { Clearfil } \\
\text { Majesty } \\
\text { ES-2 }\end{array}$ & $00025 \mathrm{~A}$ & $\begin{array}{l}\text { Kuraray } \\
\text { Noritake } \\
\text { Dental }\end{array}$ & $\begin{array}{l}\text { Bis-GMA, methacrylic } \\
\text { acid monomer, } \\
\text { silanated glass ceramic } \\
\text { fillers, surface-treated } \\
\text { microfiller CQ, } \\
\text { pigment, others }\end{array}$ & $\begin{array}{l}\text { 1. Use increments } \\
\text { of } \leq 2 \mathrm{~mm} \text {. } \\
\text { 2. Light cure for } 10 \mathrm{~s} \text {. } \\
\text { 3. Repeat steps } 1 \text { and } 2 \text {. }\end{array}$ \\
\hline
\end{tabular}




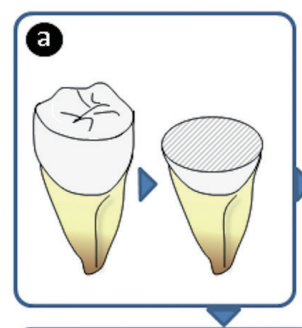

$\boldsymbol{B}$

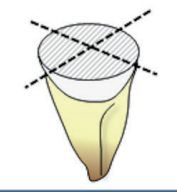

(D)

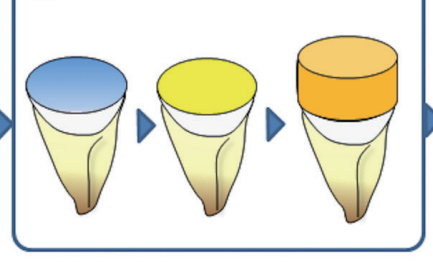

(1)

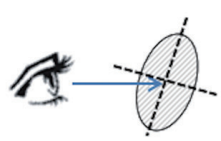

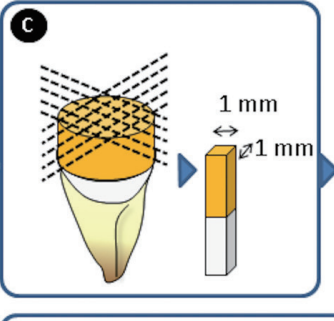
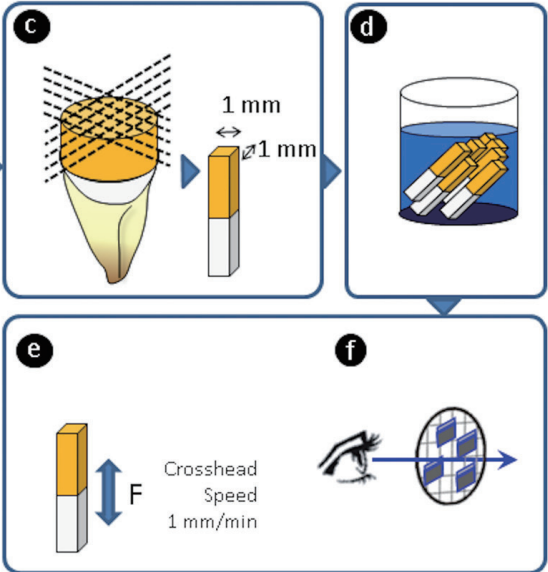

Fig. 1 Schematic illustration of the study design.

(a): Coronal dentin surfaces were obtained. (b): Surface preparation and adhesive application. (c): Rectangular beams were obtained. (d): Beams were stored in distilled water for $24 \mathrm{~h}, 6$ months, or 1 year. (e): $\mu$ TBS testing and failure mode analysis. (f): TEM observation of the adhesive interface. (g): Surface pretreatment. (h): SEM observation of the dentin surface.

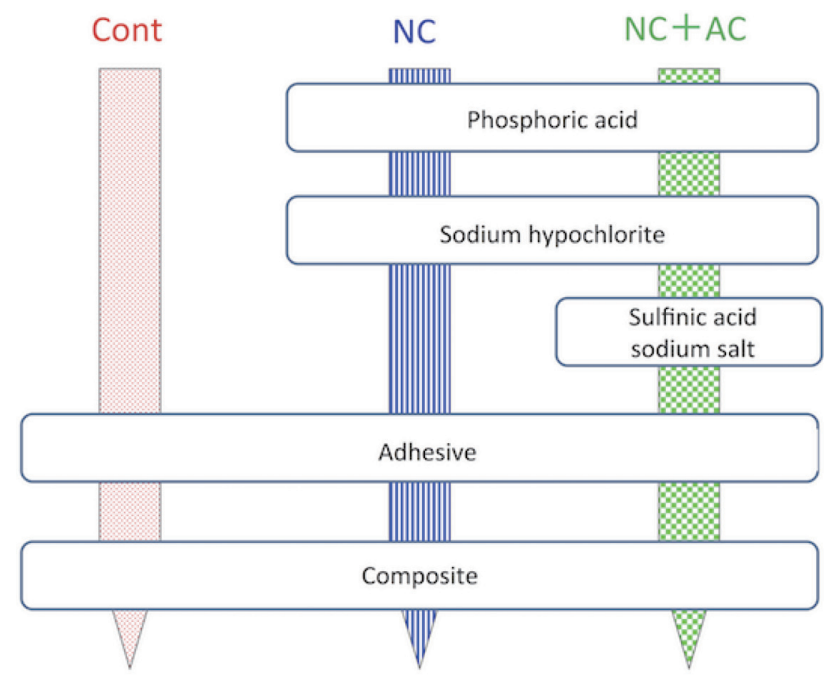

Fig. 2 Experimental groups and treatments.

Fifteen human third molars were randomly assigned into three experimental groups: no pretreatment (Cont), dentin pretreatment with phosphoric acid and sodium hypochlorite gel (NC), and additional treatment with sulfinic acid sodium salt followed by the same pretreatment of the $\mathrm{NC}$ group $(\mathrm{NC}+\mathrm{AC}) . n=5$.

Dental) was applied for $60 \mathrm{~s}$ and rinsed off. The adhesive and resin composite were then applied as described in the Cont group.

3. NC+AC group: Following the same pretreatment protocol as the NC group, sulfinic acid sodium salt (Accel, Sun Medical, Kyoto, Japan) was applied for $15 \mathrm{~s}$ and air dried. The adhesive and the composite were then applied as described in the Cont group.

Microtensile bond strength ( $\mu$ TBS) test

After 24-h water storage, teeth were sectioned perpendicular to the long axis into a series of $1-\mathrm{mm}$ thick slices under water cooling and 12-16 beams were obtained from each tooth (Fig. 1c). The beams were randomly divided into three subgroups according to the length of water storage (24 h, 6 months, and 1 year) (Fig. 1d). The beams were attached to a jig using cyanoacrylate glue (Model Repair, Dentsply Sankin, Tokyo, Japan) and subjected to tensile force at the crosshead speed of $1 \mathrm{~mm} / \mathrm{min}$ using a benchtop testing machine (EZ Test, Shimadzu, Kyoto, Japan) $(n=15)$. The cross-sectional area of each beam was measured using a digital caliper (Mitutoyo CD15, Mitutoyo, Tokyo, Japan).

\section{Failure mode analysis}

Fractured dentin surfaces were observed using an optical microscope (magnification, 30×). Failure patterns were determined and categorized as cohesive failure in dentin, cohesive failure in the composite, adhesive failure between the composite and the adhesive, adhesive failure between the adhesive and dentin, and mixed failure. Representative specimens were observed using a scanning electron microscope (SEM; JSM-6390, Nihon Denshi, Tokyo, Japan) (Fig. 1e).

\section{Transmission electron microscopy (TEM)}

Six 1-mm-thick slices for each group were randomly divided into two groups and stored in water at $37^{\circ} \mathrm{C}$ for $24 \mathrm{~h}$ or 1 year. Slices were serially sectioned perpendicular to the long axis into $400-\mu \mathrm{m}$ thickness under water cooling. Each slice was then sectioned into 
small blocks including the dentin-bond interface and fixed in $4 \%$ paraformaldehyde and $5 \%$ glutaraldehyde overnight. Samples were then dehydrated in a graded ethanol series and embedded in epoxy resin (Quetol 812, Nissin EM, Tokyo, Japan). The embedded specimens were sectioned into 70-90-nm thickness using a diamond knife (Nanotome Thick, Sakai Advanced Electron Microscope Research Center, Saitama, Japan) on an ultra-microtome (Ultrotome V, LKB, Stockholm, Sweden). The sections were finally mounted on copper grids and observed using a TEM (H-800, Hitachi, Tokyo, Japan) at an accelerating voltage of $200 \mathrm{kV}$ (Fig. 1f).

\section{Pretreated dentin surface observation}

Three human non-caries molars were stored in HBSS and used within 6 months after extraction. Mid-coronal dentin surfaces were obtained by removing the occlusal third of the molar crowns using the low-speed diamond saw under water cooling. A standard smear layer was prepared using 600 grit $\mathrm{SiC}$ paper (Fig. 1a). The dentin surface was divided into four sections and each surface was treated as follows:

1. No treatment (Cont).

2. Etching: Etch the dentin surface for $15 \mathrm{~s}$ using $37 \%$ phosphoric acid (K-Etchant gel, Kuraray Noritake Dental), rinse, and air dry.

3. NC: Etch the dentin surface using phosphoric acid, rinse, air dry, and apply $10 \% \mathrm{NaClO}$ gel (AD gel, Kuraray Noritake Dental) for $60 \mathrm{~s}$.

4. NC+AC: Etch the dentin surface using phosphoric acid, apply $\mathrm{NaClO}$ gel and sulfinic acid sodium salt (Accel, Sun Medical) for $15 \mathrm{~s}$, and air dry (Fig. 1g).

Specimens were then observed by SEM (Fig. 1h).

\section{Statistical analyses}

The $\mu$ TBS data were analyzed by two-way repeatedmeasures ANOVA and Scheffé's multiple comparison test. Additionally, the aging time effect was analyzed by one-way ANOVA and Scheffé's test. Differences were considered to be statistically significant at a level of $5 \%$.

\section{RESULTS}

$\mu$ TBS test

Mean bond strengths are summarized in Table 2 and Fig. 3. Two-way repeated-measures ANOVA revealed a significant effect of pretreatment $(p<0.001, F=23.4)$ and aging time ( $p=0.008, F=5.0$ ), but not for the correlations between individual factors $(p=0.822)$. Scheffé's multiple comparison test showed that the bond strength was significantly higher in the $\mathrm{NC}+\mathrm{AC}$ group than in the other two groups $(p<0.001)$. However, no significant difference was observed between the Cont group and the NC group $(p=0.923)$. According to one-way ANOVA, a significant influence of aging time was observed in the Cont group $(p=0.012)$. In the Cont group, Scheffé's

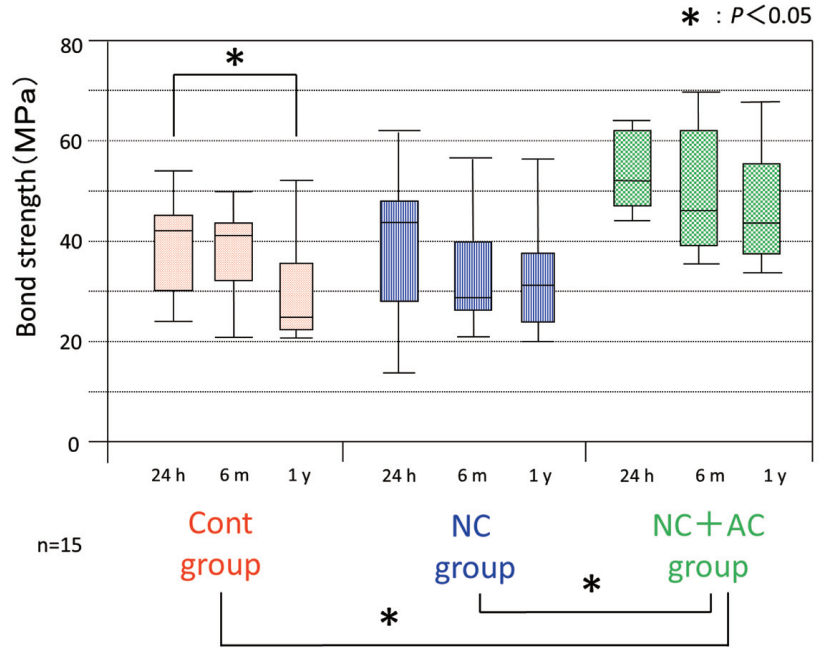

Fig. 3 Bond strengths of all groups.

The box represents the first and third quartiles. The central line represents the median. The whiskers denote the range of variance, and the outliers represent the maximum and minimum. $24 \mathrm{~h}$ : after $24 \mathrm{~h}, 6 \mathrm{~m}$ : after 6 months, 1y: after 1 year

Table 2 Microtensile bond strength and failure analysis

\begin{tabular}{llll}
\hline & & \multicolumn{2}{c}{ Aging Time } \\
\cline { 2 - 4 } Group & \multicolumn{1}{c}{$24 \mathrm{~h}$} & 6 months & 1 year \\
\hline \multirow{2}{*}{ Cont } & $\begin{array}{l}38.4(10.5) \mathrm{a} \\
(2 / 4 / 0 / 3 / 6)\end{array}$ & $35.9(10.6) \mathrm{a}, \mathrm{b}$ & $\begin{array}{c}(0 / 2 / 2 / 0 / 11) \\
(11.1) \mathrm{b}\end{array}$ \\
& $39.3(15.6)$ & & $33.0(13.4)$ \\
NC & $(0 / 2 / 2 / 0 / 11)$ & $33.2(11.7)$ & $(0 / 7 / 1 / 0 / 7)$ \\
& $53.3(9.7)$ & $50.0(11.8)$ & $45.8(12.9)$ \\
NC+AC & $(0 / 1 / 2 / 0 / 12)$ & $(1 / 5 / 1 / 0 / 8)$ \\
\hline
\end{tabular}

Numbers in parentheses in the upper line refer to \pm standard deviation and numbers in parentheses in the lower line refer to number of beams per failure mode as follows: cohesive in dentin/cohesive in the composite/interface between the adhesive and dentin/interface between the composite and the adhesive/mixed. Within Cont group, means with same letters are not statistically different. 

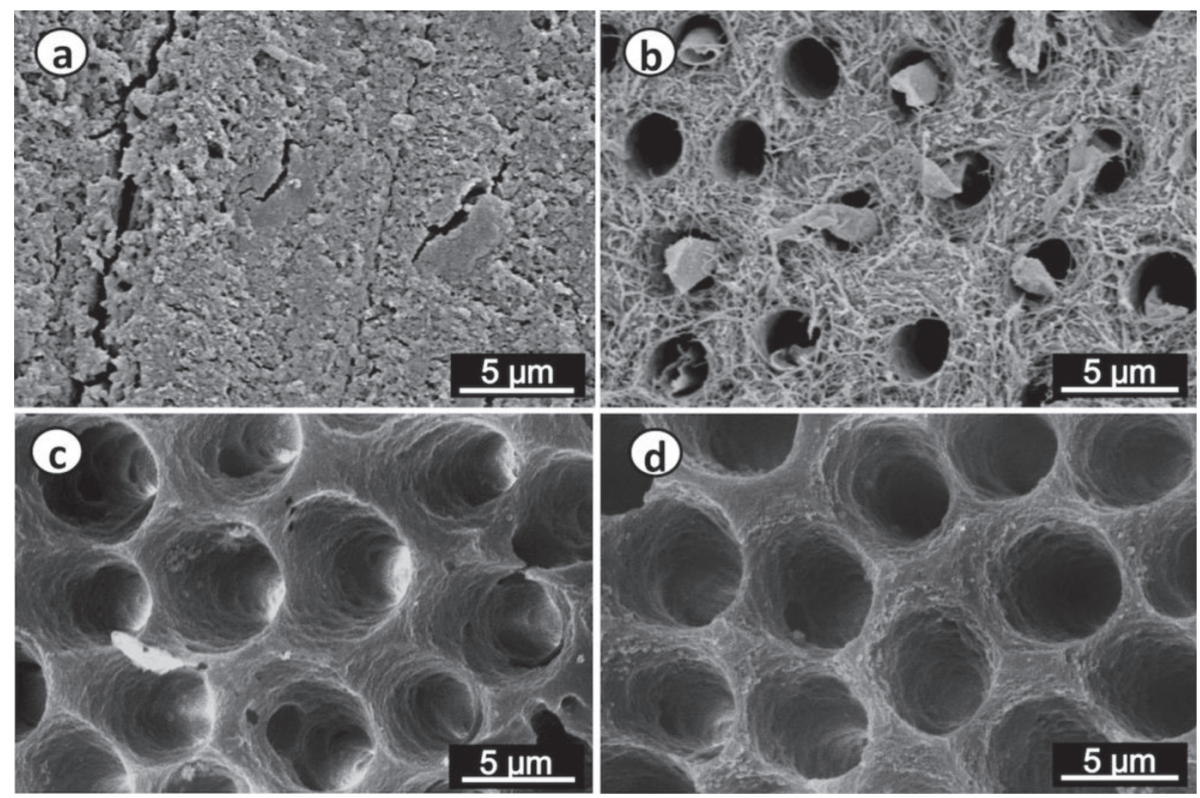

Fig. 4 Representative SEM photomicrographs of the dentin surface.

(a): The dentin surface in the Cont group is covered by a smear layer. (b): After phosphoric acid treatment. Complete absence of the smear layer and collagen fibrils is observed. (c): In the NC group, collagen fibrils are removed and dentin tubules are observed. (d): The dentin surface in the $\mathrm{NC}+\mathrm{AC}$ group is similar to that in the $\mathrm{NC}$ group.

multiple comparison test showed a significant difference between 24 -h and 1-year subgroups $(p=0.012)$.

\section{Pretreated dentin surface observation}

The dentin surface was covered by the smear layer in the Cont group (Fig. 4a). However, the smear layer was removed by phosphoric acid processing and a collagen fiber layer was observed on the surface during the etching process (Fig. 4b). The collagen fiber layer was then removed and the diameter of dentin tubules increased after applying $\mathrm{NaClO}$ (Fig. 4c). After sulfinic acid sodium salt application, obvious changes were not observed (Fig. 4d).

\section{Failure mode analysis}

Mixed failure predominantly occurred in all groups, followed by cohesive failure in the composite except for the $\mathrm{NC}+\mathrm{AC}$ group at $24 \mathrm{~h}$ (Table 2). Interface failure between the composite and the adhesive was observed only in the Cont group at $24 \mathrm{~h}$ (Table 2, Fig. 5a). Concerning mixed failure in the Cont group, the adhesive-dentin interface was seldom observed in the 24-h subgroup, though the adhesive-dentin interface was more frequently observed in the 1-year subgroup (Fig. $5 \mathrm{~b})$. The $\mathrm{NC}$ group and the $\mathrm{NC}+\mathrm{AC}$ group demonstrated a similar trend in that there was no clear difference between 24-h and 1-year subgroups except cohesive failure in the composite was increased (Table 2). SEM observation of the fractured surface showed a similar

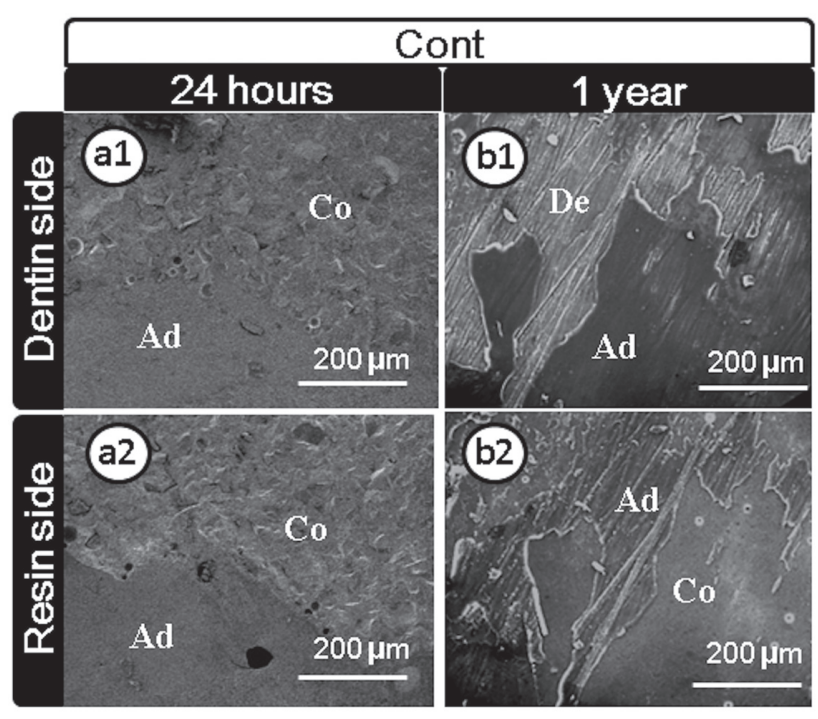

Fig. 5 Representative SEM photomicrographs of the fractured surface after $\mu$ TBS testing.

(a): The Cont group at $24 \mathrm{~h}$. The adhesive and the composite are observed on both the dentin side (a1) and the resin side (a2), showing interface failure between the adhesive and the composite. (b): The Cont group at 1 year. Dentin and the adhesive are observed on the dentin side (b1) while the adhesive and the composite are observed on the resin side (b2), showing mixed failure. Ad: adhesive, Co: composite, De: dentin. 


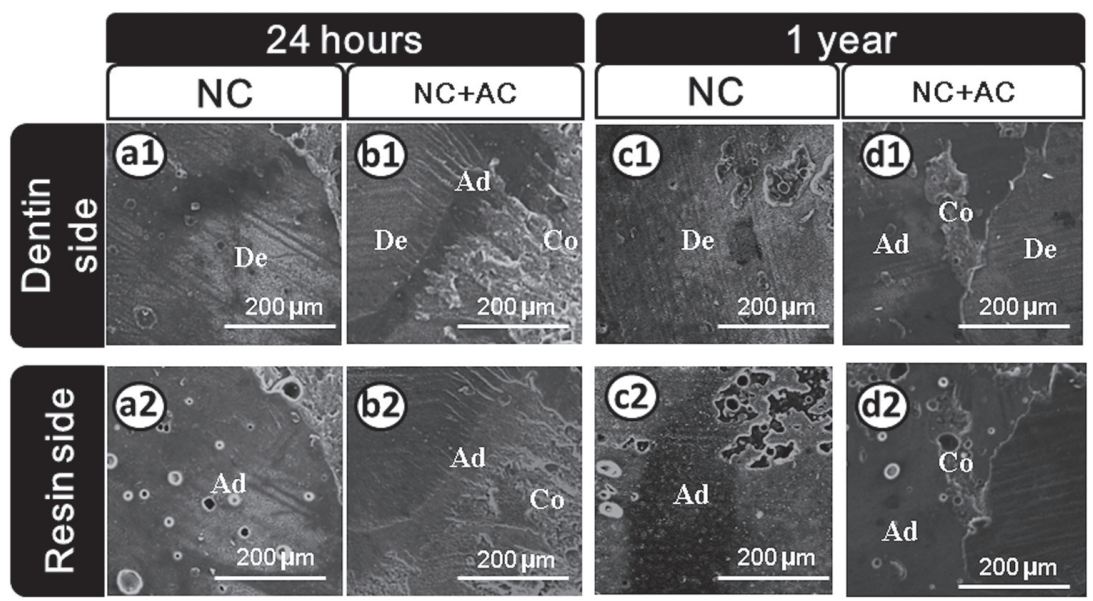

Fig. 6 Representative SEM photomicrographs of the fracture surface.

(a): The NC group at $24 \mathrm{~h}$. Dentin is observed on the dentin side (a1) while the adhesive is observed on the resin side (a2), showing interface failure between dentin and the adhesive. (b): The NC+AC group at 24 h. Dentin, the adhesive, and the composite are observed on the dentin side (b1) while the adhesive and the composite are observed on the resin side (b2), showing mixed failure. (c): The NC group at 1 year. Dentin is observed on the dentin side (c1) while the adhesive is observed on the resin side (c2), showing interface failure between dentin and the adhesive. (d): The NC+AC group at 1 year. Dentin, the adhesive, and the composite are observed on the dentin side (d1) while the adhesive and the composite are observed on the resin side (d2), showing mixed failure. Ad: adhesive, Co: composite, De: dentin.

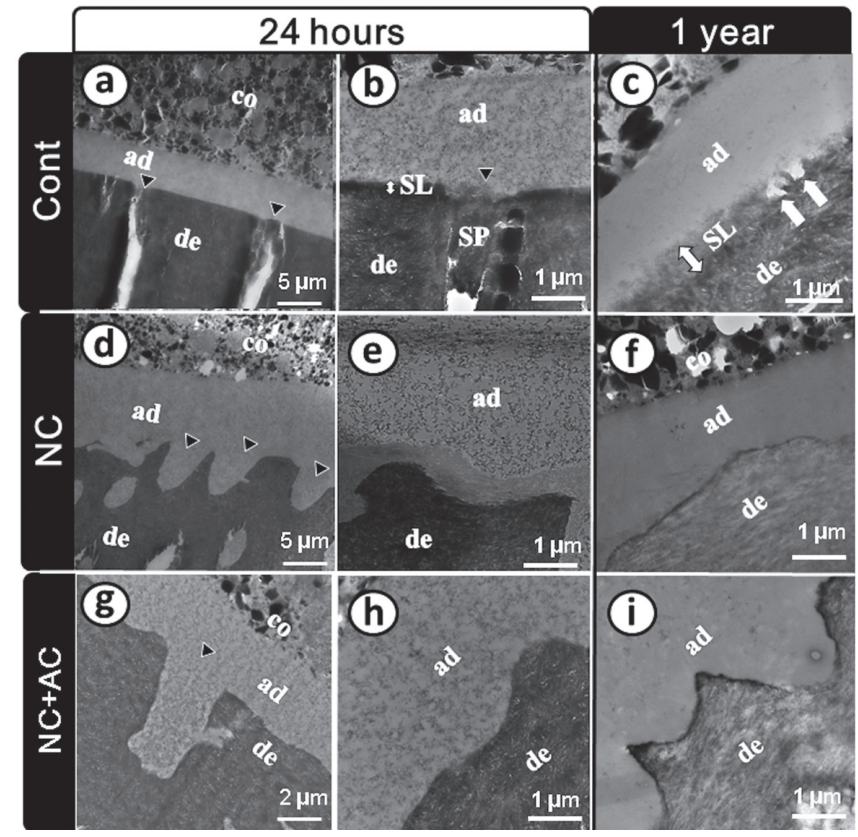

Fig. 7 Representative TEM photographs of the adhesive interface.

(a): The Cont group at $24 \mathrm{~h}$. (b): Magnified image $(15,000 \times)$ of (a). The smear layer (SL) is observed below the adhesive layer, and a smear plug (SP) is observed in a dentin tubule. (c): The Cont group at 1 year, magnified image $(15,000 \times)$. A gap (white arrow) is observed between the adhesive layer and the dentin layer. (d): The NC group at 24 h. Dentin tubules are open and the adhesive fills dentin tubules, forming resin tags. (e): Magnified image $(15,000 \times)$ of (d). Collagen fibrils $(1 \mu \mathrm{m})$ are observed. (f): The NC group at 1 year, magnified image $(15,000 \times)$. No gap is observed between the adhesive layer and the dentin layer. (g): The NC+AC group at $24 \mathrm{~h}$. (h): Magnified image (15,000×) of (g). No smear layer (SL) and no smear plug (SP) is observed. Resin tags are observed. (i): The NC+AC group at 1 year, magnified image $(15,000 \times)$. No gap is observed between the adhesive layer and dentin layer. ad: adhesive, co: composite, de: dentin, SL: smear layer, SP: smear plug. Black arrowheads indicate dentin tubules, white arrows indicate gaps, and double-headed white arrows indicate the smear layer. 
tendency between the $\mathrm{NC}$ group and the $\mathrm{NC}+\mathrm{AC}$ group (Figs. 6a-d).

\section{TEM observation of the adhesive interface}

The smear layer and smear plugs were observed in the Cont group (Figs. 7a, b), as seen under SEM surface observation (see Fig. 4a), and resin tags were not observed. A clear defect was not visible at the dentinadhesive interface at $24 \mathrm{~h}$ in the Cont group. However, a gap existed in the smear layer at 1 year (Fig. 7c). In the $\mathrm{NC}$ group and the $\mathrm{NC}+\mathrm{AC}$ group, the smear layer and decalcified collagen fibrils were removed. As a result, resin tags formed (Figs. $7 d$, g). There was no clear difference between the 24-h and 1-year subgroups in both groups (Figs. 7f, i).

\section{DISCUSSION}

The present study evaluated the effect of reducing agent interposition after NC treatment to improve dentin bonding durability of mild type one-step self-etching adhesive. In this study, flat coronal dentin and photo cure resin composite (i.e., not root canal and resin composite for core buildup) were used because more beams per tooth could be obtained from flat coronal dentin than root canal wall dentin and aged samples could be obtained from the same tooth. Resin composite for core buildup would require mixing two pastes, which could incorporate air bubbles that have an unclear effect on the bond strength. Conversely, one photo cure resin paste may prevent air bubbles. Therefore, we considered photo cure resin composite would more accurately reflect the effect of sodium sulfinic acid salt treatment on the bond strength. As a result, there was no significant difference between the Cont group and the NC group in $\mu$ TBS. Therefore, the null hypothesis - there is no positive effect on dentin bonding by NC treatmentwas accepted. According to the failure mode analysis after bond strength testing, interface failure between the composite and the adhesive was observed only in the Cont group at $24 \mathrm{~h}$ and the dentin-adhesive interface was seldom observed in the Cont group at 24 h. However, it was more frequently observed in the NC group and the $\mathrm{NC}+\mathrm{AC}$ group. SEM observation after $\mathrm{NC}$ treatment revealed removal of the smear layer and open dentin tubules, which increased mechanical interaction with the adhesive (i.e., a resin tag) (Fig. 4). These results indicated the initial adhesive interface between dentin and the adhesive of the Cont group is reliable even without mechanical interaction. The relationship between bond strengths and failure modes hardly existed and mixed failure predominantly occurred in all groups. The results revealed that the adhesive used in the current study was satisfactory, at least in the immediate period. The adhesive included 10-methacryloyloxydecyl dihydrogen phosphate (10-MDP) as the functional monomer. 10-MDP has been reported as a promising functional monomer for dentin bonding in clinical settings ${ }^{18)}$ and shown to bond chemically with calcium ions in the apatite surface ${ }^{19)}$.
Some studies reported that NC treatment could improve bond strength and durability ${ }^{20)}$, whereas other studies reported that it decreased bond strength and caused microleakage ${ }^{21}$. In this study, the application time of phosphoric acid and $\mathrm{NaClO}$ gel was 15 and 60 $\mathrm{s}$, respectively. Wakabayashi et al. reported a sufficient bonding effect of 15-s phosphoric acid application and 60-s $\mathrm{NaClO}$ gel application ${ }^{17)}$. After NC treatment, the smear layer and collagen fibrils on the dentin surface appeared to be removed completely under SEM observation as mentioned above. However, TEM observation revealed a decalcified collagen layer remained in some areas in the $\mathrm{NC}$ group, indicating that the effect of $\mathrm{NaClO}$ gel may vary. As the decalcified collagen layer has been thought to create a weak area, we speculate that this layer influenced the mean bond strength of the NC group. In the present study, the flat dentin surface was considered to be an easily removable collagen layer rather than the dentin surface in clinical settings, which is thought to be more difficult to manipulate. Therefore, a negative effect of NC treatment may be readily observed when phosphoric acid and $\mathrm{NaClO}$ gel are used in dentin in clinical settings.

Between the $\mathrm{NC}+\mathrm{AC}$ group and the NC group, a significant difference in bonding effectiveness was observed. Therefore, the second null hypothesis - there is no positive effect on dentin bonding by sulfinic acid sodium salt interposition- was rejected. This outcome corroborates a previous report which demonstrated bond strengths of NaClO-treated dentin could be restored by application of sodium sulfinic acid ${ }^{13,14)}$. The authors concluded that the application of Accel for 5 or $10 \mathrm{~s}$ improved bond strengths of $\mathrm{NaClO}$-treated dentin. Taniguchi et al. also reported that 30-s application of Accel improved the bond strength of $\mathrm{NaClO}$-treated dentin. Ascorbate acid and sodium ascorbate are also used as reducing agents in clinical practice ${ }^{14)}$. Yiu et al. reported additional treatment with sodium ascorbate restored bond strengths after $\mathrm{NaClO}$ treatment ${ }^{22)}$. Additionally, Morris et al. found that $\mathrm{NaClO}$ and EDTA agents produced significantly large reductions in resindentin bond strengths, which could be completely reversed by application of either $10 \%$ ascorbic acid or $10 \%$ sodium ascorbate ${ }^{10)}$. Prasansuttiporn et al. also reported that application of Accel after $\mathrm{NaClO}$ treatment could obtain higher bond strengths than application of sodium ascorbate $^{13)}$. Taken together, the effectiveness of sodium sulfinic acid was not inferior to that of other reducing agents. Because sodium sulfinic acid can be stored for prolonged periods, it is preferred in clinical settings.

This study evaluated not only immediate bond strength, but also bonding durability. In the Cont group, there was a significant difference between the 24-h and 1-year subgroups. However, no significant effect of water aging was observed in the $\mathrm{NC}$ group and the $\mathrm{NC}+\mathrm{AC}$ group. Therefore, the third null hypothesis - 1-year water storage has no influence on bonding ability- was accepted for the $\mathrm{NC}$ and $\mathrm{NC}+\mathrm{AC}$ groups and rejected for the Cont group. In the Cont group, bond strengths significantly decreased by water aging and failure in 
the dentin-adhesive interface, including specimens counted as mixed failure, was more frequently observed in the 1-year subgroup than in the 24-h subgroup. Moreover, a clear gap in the smear layer and degradation at the bottom of the smear layer were observed in the Cont group at 1 year by TEM. Conversely, in the $\mathrm{NC}$ group and the NC+AC group, bond strengths significantly decreased and remarkable morphological changes were not detected by TEM and SEM. Kodama evaluated the effect of NC treatment using Panavia 21, a conventional dual-cure resin cement, and concluded that NC treatment improved resin-dentin bond durability ${ }^{20)}$. Degradation of collagen fibers is one of the main factors associated with bonding durability. Thus, the removal of collagen at the bonded interface seems to be effective. These factors are responsible for a greater infiltration of adhesive systems in dentin ${ }^{23)}$. The findings of the present study, which used a mild type one-step self-etching adhesive, suggest that the remnant smear layer has a negative effect on bond durability. In clinical practice, the dentin surface would be covered by temporary cement, dental plaque, and/or saliva, and some bacteria may be trapped in the smear layer. NC treatment can remove not only the smear layer and decalcified collagen, but also these chemical and biological contaminants. Therefore, NC treatment might be more effective in clinical practice than in vitro conditions.

The simplified one-step system is gaining attention in clinical practice ${ }^{24)}$. However, this adhesive system has inadequate decalcification ability, thus the smear layer is not completely removed. The present study showed that the bond strength of the Cont group, which used a mild type one-step system adhesive containing 10-MDP that was thought to be resistant to degradation, was significantly decreased after water aging. NC treatment was anticipated to resolve this shortcoming. However, some studies reported that NC treatment performed better in dual-cure cement systems ${ }^{17,20)}$ but was unsuitable for 4-META/MMA-TBB resin cement. Moreover, the application of antioxidants can increase bond strengths ${ }^{15)}$. These results suggest that the deproteinization effect of NC might be adhesivedependent and the application of antioxidants after deproteinization may be beneficial only in select adhesive systems. Thus, further studies evaluating various adhesive systems are needed to validate this technique.

\section{CONCLUSION}

According to the results of this study, we confirmed the effectiveness of the following steps before application of mild type one-step adhesive to dentin: 1) application of phosphoric acid and $\mathrm{NaClO}$ to improve bonding durability and 2) application of sodium sulfinic acid salt after NC treatment to improve bonding effectiveness.

\section{ACKNOWLEDGMENTS}

This work was supported by a KAKENHI Grant-in Aid for Scientific Research (No. 26670834). The authors would like to express our gratitude to Kuraray Noritake Dental for the generous donation of materials used in this study.

\section{CONFLICTS OF INTEREST}

The authors deny any conflicts of interest related to this study.

\section{REFERENCES}

1) Peumans M, Kanumilli P, De Munck J, Van Landuyt K, Lambrechts P, Van Meerbeek B. Clinical effectiveness of contemporary adhesives: a systematic review of current clinical trials. Dent Mater 2005; 21: 864-881.

2) Mine A, De Munck J, Cardoso MV, Van Landuyt KL, Poitevin A, Van Ende A, Matsumoto M, Yoshida Y, Kuboki T, Yatani H, Van Meerbeek B. Dentin-smear remains at self-etch adhesive interface. Dent Mater 2014; 30: 1147-1153.

3) Belli R, Sartori N, Peruchi LD, Guimarães JC, Vieira LC, Baratieri LN, Monteiro S Jr. Effect of multiple coats of ultramild all-in-one adhesives on bond strength to dentin covered with two different smear layer thicknesses. J Adhes Dent 2011; 13: 507-516.

4) Suyama Y, Lührs AK, De Munck J, Mine A, Poitevin A, Yamada T, Van Meerbeek B, Cardoso MV. Potential smear layer interference with bonding of self-etching adhesives to dentin. J Adhes Dent 2013; 15: 317-324.

5) Van Meerbeek B, Peumans M, Gladys S, Braem M, Lambrechts P, Vanherle G. Three-year clinical effectiveness of four totaletch dentinal adhesive systems in cervical lesions. Quint Int 1996; 27 : 775-784.

6) Perdigão J, Lopes M, Geraldeli S, Lopes GC, García-Godoy F. Effect of a sodium hypochlorite gel on dentin bonding. Dent Mater 2000; 16: 311-323.

7) Tanaka J, Nakai H. Application of root canal cleaning agents having dissolving abilities of collagen to the surface treatment for enhanced bonding of resin to dentin. Dent Mater J 1993; 12: 196-208.

8) Pioch T, Kobaslija S, Huseinbegović A, Müller K, Dörfer $\mathrm{CE}$. The effect of $\mathrm{NaOCl}$ dentin treatment on nanoleakage formation. J Biomed Mater Res 2001; 56: 578-583.

9) Kashiwada T. Development of new dental treatment using adhesive technique. Ann Jpn Prosthodont Soc 1997; 41: 746762. (In Japanese)

10) Morris MD, Lee KW, Agee KA, Bouillaguet S, Pashley DH. Effects of sodium hypochlorite and RC-prep on bond strengths of resin cement to endodontic surfaces. J Endod 2001; 27: 753757.

11) Erdemir A, Ari H, Güngüneş H, Belli S. Effect of medications for root canal treatment on bonding to root canal dentin. J Endod 2004; 30: 113-116.

12) Rueggeberg FA, Margeson DH. The effect of oxygen inhibition on an unfilled/filled composite system. J Dent Res 1990; 69: 1652-1658.

13) Prasansuttiporn T, Nakajima M, Kunawarote S, Foxton RM, Tagami J. Effect of reducing agents on bond strength to NaOCl-treated dentin. Dent Mater 2011; 27: 229-234.

14) Taniguchi G, Nakajima M, Hosaka K, Iwamoto N, Ikeda M, Foxton RM, Tagami J. Improving the effect of $\mathrm{NaOCl}$ pretreatment on bonding to caries-affected dentin using selfetch adhesives. J Dent 2009; 37: 769-775.

15) Li X, Ma W, Chen X, Zhao J, Nakata T, Tanaka K, Takahashi K, Nishitani Y, Yoshiyama M. Bonding to NaOCl-treated dentin: effect of pretreatment with sodium toluene sulfinic acid. J Adhes Dent 2012; 14: 129-136. 
16) Arrais CA, Giannini M, Rueggeberg FA. Effect of sodium sulfinate salts on the polymerization characteristics of dualcured resin cement systems exposed to attenuated lightactivation. J Dent 2009; 37: 219-227.

17) Wakabayashi H, Fujita E, Kondo Y, Suzuki K, Yamashita A. The effect of dentin treatment on adhesive composite resin to dentin -viscous dissolution of collagen. Ann Jpn Adhes Dent Soc 1992; 10: 187-195. (In Japanese)

18) Inoue S, Murata $\mathrm{Y}$, Sano $\mathrm{H}$, Kashiwada T. Effect of $\mathrm{NaOCl}$ treatment on bond strength between indirect resin corebuildup and dentin. Dent Mater J 2002; 21: 343-354.

19) Yoshihara K, Yoshida Y, Hayakawa S, Nagaoka N, Irie M, Ogawa T, Van Landuyt KL, Osaka A, Suzuki K, Minagi S, Van Meerbeek B. Nanolayering of phosphoric acid ester monomer on enamel and dentin. Acta Biomater 2011; 7: 31873195 .
20) Kodama T. A study on dentin bonding-effect of surface pretreatment on adhesion to dentin. Ann Jpn Adhes Dent Soc 1997; 15: 1-20. (In Japanese)

21) Frankenberger R, Krämer N, Oberschachtsiek H, Petschelt A. Dentin bond strength and marginal adaption after $\mathrm{NaOCl}$ pre-treatment. Oper Dent 2000; 25: 40-45.

22) Yiu CK, García-Godoy F, Tay FR, Pashley DH, Imazato S, King NM, Lai SC. A nanoleakage perspective on bonding to oxidized dentin. J Dent Res 2002; 81: 628-632.

23) Prati C, Chersoni S, Pashley DH. Effect of removal of surface collagen fibrils on resin-dentin bonding. Dent Mater 1999; 15: 323-331.

24) Van Meerbeek B, Van Landuyt K, De Munck J, Hashimoto M, Peumans M, Lambrechts P, Yoshida Y, Inoue S, Suzuki K. Technique-sensitivity of contemporary adhesives. Dent Mater J 2005; 24: 1-13. 